\title{
Study of Genetic Diversity of Recombinant Inbred Lines in Bread Wheat (Triticum aestivum L.) for Heat Tolerance
}

\author{
Harpreet Singh*, Bikram Singh, Surbhi Kohli, Ashish Sheera, \\ Om Prarkash and Faisal Butt
}

Sher-e-Kashmir University of Agriculture Science and Technology 180009, Chatha, Jammu and Kashmir, India

*Corresponding author

\section{A B S T R A C T}

Keywords

Heat stress, Divergence,

Canopy temperature, Relative water content

Article Info

Accepted:

10 January 2021

Available Online:

10 February 2021
As a cool season crop, wheat (Triticum aestivum L.) has maximum growing temperature of $15^{\circ} \mathrm{C}$ during the reproductive stage. With increase in global climate change, heat stress is becoming an increasingly severe constraint on production of wheat. An experiment was conducted on 32 bread wheat genotypes to evaluate the genetic diversity for yield and yield contributing parameters under heat stress conditions. The genotypes were congregated into six clusters namely cluster I having 25 genotypes, followed by cluster v (3) and cluster II, III, IV and VI each having one genotype each. The maximum inter cluster distance was observed between genotype of the cluster II and VI (96.6). Among all characters number of days to fifty per cent flowering (40\%), relative water content (16.44) and flag leaf area (15.52) contributed maximum to divergence.

\section{Introduction}

Bread wheat (Tritium aestivum L.) is a selfpollinating annual plant, belonging to the family poaeceae. It is a hexaploid (AABBDD) with chromosome number of $42(2 n=6 x=42)$ and a genome size of 16 GB. Globally, wheat production stands at 768.49 million metric tonnes with an area of 220.24 million hectares and productivity of 3.49 metric tonnes per hectare (USDA 2020/21). Heat stress is an international issue related to adverse effect on agriculture that causes morpho-physiological, anatomical and biochemical changes resulted in heavy losses in crop production (Wahid et al., 2007).

Moisture stress at post- anthesis, decreases duration of maturation, grain filling, grain yield, mean grain weight, grain number and 1000-grain weight (Kaur and Behl, 2010). Heat stresses during grain filling results in 
decrease in starch contents reducing the grain quality as well as grain weight (Sial et al., 2005). However, the average global temperature is reported to be increasing at a rate of $0.18^{\circ} \mathrm{C}$ every decade (Hansen et al., 2012). Heat stress results in deterioration of cellular structure and results in damage to various plant metabolic pathways, mainly those concerning to membrane thermostability, photosynthesis and starch synthesis (Larkindale et al., 2002). Denaturation of proteins caused by heat stress disrupts water, ion, and organic solute movement across membrane, resulting in increased cell membrane permeability, and in turn, inhibition of cellular function (Cossani. 2002). Thylakoid membranes and PS II are considered the most heat-labile cell components (Ristic et al., 2007). Under high temperature thylakoid membranes causes swelling, increased leakiness, physical separation of the chlorophyll light harvesting complex II from the PSII core complex, and damage of PSII-mediated electron transfer (Ristic et al., 2008). Starch synthesis is highly sensitive to high temperature stress due to the susceptibility of the soluble starch synthase in developing wheat kernels (Keeling et al., 1994).

Genetic diversity is essential for adaptability and survival of wheat species against abiotic and biotic stress (Fu and Somers 2009). Diversity originates either due to geographical separation or due to genetic barriers and it plays crucial role in plant breeding. Genetic divergence analysis decides the level of diversity present among selected genotypes (Mondal. 2003). Study on the nature and degree of genetic diversity assists the plant breeder in selecting the diverse parents for purposeful hybridization (Samsuddin et al., 1985). The $\mathrm{D}^{2}$ statistics (Mahalanobis. 1936) is one of the most scientific biometrical techniques to determine genetic divergence present in a population. Selection of parents based on genetic divergence has been successfully exploited in several crops (Jain et al., 1981). Present experiment was conducted to identify genetically diverse genotypes among RILs as donors with desirable traits for hybridization particularly for heat stress with high yield and its contributing traits.

\section{Materials and Methods}

\section{Plant material and field trails}

The experiment was planted during Rabi 2017-2018 and Rabi 2018-19 at the Experimentation Centre of Department of Genetics and Plant Breeding, Faculty of Agriculture. Sher-e-Kashmir University of Agricultural Science and Technology of Jammu, Chatha which is situated at an altitude of $332 \mathrm{~m}$ above sea level with $32039^{\prime \prime}$ degree $\mathrm{N}$ latitude and 740 degree 58 " E longitude with an annual rainfall of $1000 \mathrm{~mm}$ and, represents sub-tropical conditions.

The experimental material consist of 450 recombinant inbred lines population derived from three crosses (LOK-1 $\times$ HUW- 468, LOK $1 \times$ HUW 234 and Raj-4014 × PBN-51 ) which were grown during Rabi 2017-2018 in an augmented design with two checks namely PBN 51 (heat tolerant) and HUW 234 (heat susceptible) line. After every 20 lines, a total of 450 RILs were further evaluated for various morpho-physiological characters. Based on the mean data of 450 lines, 10 RILs from each of the three crosses were selected exhibiting better morpho-physiological character. Total of 30 RIL along with two check namely PBN 51 and HUW 234 were evaluated during Rabi 2018-2019 in two rows of five meter using RBD design in three replication for morphological and physiological traits to select elite RILs for heat tolerance and grain yield. The meteorological data for experimental period were obtained from Meteorological Station, SKUAST-J Chatha 
Jammu. There were 77 days with temperature above $25^{\circ} \mathrm{C}$. These days coincided with flowering and grain filling stages which are most critical stages that determine yield. There were several temperature peaks before and during flowering.

Data were recorded on five randomly selected competitive plants from each plot on thirteen quantitative characters namely Plant yield (g), and yield attributing trait such as number of days to flowering, number of days to maturity, plant height $(\mathrm{cm})$, number of tillers per plant, number of grains per ear, thousand grain weight $(\mathrm{g})$, flag leaf area $\left(\mathrm{cm}^{2}\right)$, chlorophyll content (SPAD unit), relative water content $(\%)$, relative water loss (\%). canopy temperature $\left({ }^{0} \mathrm{C}\right)$ and canopy temperature depression $\left({ }^{\circ} \mathrm{C}\right)$.

The analysis of recorded data was done for genetic diversity by using Mahalanobis $\mathrm{D}^{2}$ statistic (Mahalanobis. 1956) and clustering of the genotypes was done according to Tocher's method (Rao. 1952). The analysis was done using window stat software.

\section{Genetic divergence analysis}

Based on Mahalanobis $\mathrm{D}^{2}$ analysis thirty two genotypes were grouped into six clusters depicted in table 1. Verma et al., (2014) referred to cluster analysis as the art of finding group. The aim of clustering is to find groups that are very diverse from each other, and whose members are very analogous to each other.

The grouping pattern of the genotypes suggested no parallelism between genetic divergence and geographical distribution of genotypes. (Singh et al., 2012), (Lokhande et al., 1987) and (Mohanty and Prusti, 2002) described that genotype diversity was independent of geographical region. In present investigation Cluster 1 had maximum genotypes (25), followed by cluster fifth (1). Second, third, fourth and sixth cluster had one genotype only. On the basis of dissimilarity coefficient at $50 \%$ from the dendogram. (Hailegiorgis et al., 2011) grouped the 49 bread wheat genotypes into 22 different clusters with cluster 9 and 13 deserve for their direct use as parents in hybridization programs for the development of high yielding varieties. (Singh et al., 2011) clustered 60 genotypes of bread wheat into six clusters,.

To get more heterotic and largest number of desirable transgressive segregants, selection of parents for hybridization should be evaluated on basis of genetic diversity rather than geographic diversity.

\section{Intra and inter cluster distances}

The intra and inter cluster distance values between six clusters is presented in table 2 . The magnitude of intra cluster distances measure the extent of genetic diversity between the cultivars of same cluster.

Inter cluster distance is a method to determine of genetic distance between two clusters. The genotype of the cluster II and VI exhibited maximum divergence (96.06) followed by the genotypes of cluster III and VI (79.73), V and VI (71.26), IV and VI (61.08), I and VI (60.23), II and IV (58.53), III and IV (54.61). The average inter cluster distance between the genotypes of cluster I (21.82) was maximum followed by clusters $\mathrm{V}$ (12.62).

Highest inter-cluster distance than intra-cluster distance, shows wide genetic diversity among the genotypes. More the distance between the clusters wider the genetic diversity would be present between the genotypes. Highly divergent genotypes would produce a broad range of segregation in the successive generations facilitating further selection of desirable genotypes. (Singh et al., 2012) 
Table.1 Distribution pattern of 32 genotypes of wheat in various clusters (I-VI) for various heat related traits.

\begin{tabular}{|c|c|c|}
\hline Clusters No. & No. of Genotype & Name of Genotypes \\
\hline I & 25 & Cross 1 RIL 1,2,3,4,5,6,7,8,10. Cross 2 RIL 11, 12, 13,14,16,17,18,19,20. Cross \\
\hline II & 1 & 3 RIL 21, 22, 26, 27, 29. Check HUW 234 \\
\hline III & 1 & Cross 3 RIL 15 \\
\hline IV & 1 & Cross 2 RIL 15 \\
\hline V & 3 & Check PBN 51 \\
\hline VI & 1 & Cross 1 RIL 9, Cross 3 RIL 24,28 \\
\hline
\end{tabular}

Table.2 Inter and intra (diagonal) cluster average distance of $\mathrm{D}^{2}$ among different clusters in wheat to study genetic divergence among various RILs

\begin{tabular}{|c|c|c|c|c|c|c|}
\hline & Cluster I & Cluster II & Cluster III & Cluster IV & Cluster V & Cluster VI \\
\hline Cluster I & $\mathbf{2 1 . 8 2}$ & 33.45 & 30.93 & 34.43 & 37.67 & 60.23 \\
\hline Cluster II & & $\mathbf{0 . 0 0}$ & 8.94 & 58.53 & 23.21 & 96.06 \\
\hline Cluster III & & & $\mathbf{0 . 0 0}$ & 54.61 & 22.29 & 79.73 \\
\hline Cluster IV & & & & $\mathbf{0 . 0 0}$ & 45.51 & 61.08 \\
\hline Cluster V & & & & & $\mathbf{1 2 . 6 2}$ & 71.26 \\
\hline Cluster VI & & & & & & $\mathbf{0 . 0 0}$ \\
\hline
\end{tabular}


Table.3 Cluster mean values of six clusters for various characters of 32 wheat genotype.

\begin{tabular}{|c|c|c|c|c|c|c|}
\hline Character/Cluster & I & II & III & IV & V & VI \\
\hline $\begin{array}{l}\text { Number of days to fifty percent } \\
\text { flowering }\end{array}$ & 97.90 & 103.67 & 101.45 & 102.00 & 103.33 & 78.67 \\
\hline Number of days to maturity & 120.13 & 105.33 & 122.33 & 117.67 & 108.67 & 128.67 \\
\hline Plant height $(\mathrm{cm})$ & 86.20 & 72.54 & 69.51 & 116.78 & 82.35 & 76.36 \\
\hline Number of tillers per plant & 9.07 & 8.56 & 9.22 & 10.60 & 8.19 & 8.33 \\
\hline Number of grains per ear & 41.07 & 41.89 & 39.78 & 37.09 & 38.55 & 37.78 \\
\hline Thousand grain weight (g) & 30.36 & 36.71 & 29.34 & 33.67 & 30.32 & 33.29 \\
\hline Flag leaf area $\left(\mathrm{cm}^{2}\right)$ & 32.91 & 31.76 & 31.15 & 31.43 & 22.04 & 25.33 \\
\hline Chlorophyll content & 38.66 & 38.88 & 41.44 & 41.78 & 38.31 & 38.47 \\
\hline Relative water content (\%) & 57.55 & 54.48 & 53.18 & 59.59 & 55.87 & 50.88 \\
\hline Relative water loss (\%) & 75.90 & 74.10 & 76.40 & 67.52 & 73.84 & 74.74 \\
\hline Canopy temperature $\left({ }^{0} \mathrm{C}\right)$ & 21.54 & 26.87 & 21.03 & 20.65 & 21.01 & 21.51 \\
\hline $\begin{array}{l}\text { Canopy temperature depression } \\
\left({ }^{0} \mathrm{C}\right)\end{array}$ & 7.64 & 7.27 & 7.30 & 6.22 & 7.50 & 7.14 \\
\hline Grain yield $^{-1}$ & 16.21 & 16.77 & 16.42 & 20.16 & 16.80 & 18.08 \\
\hline
\end{tabular}

Table.4 Percent contribution towards variability of each character for 32 wheat genotype for various heat related traits

\begin{tabular}{|c|c|c|}
\hline S.No & Character & Contribution \% \\
\hline 1 & Number of days to fifty per cent flowering & 40.32 \\
\hline 2 & Number of days to maturity & 7.46 \\
\hline 3 & Plant height $(\mathbf{c m})$ & 2.02 \\
\hline 4 & Number of tillers per plant & 3.63 \\
\hline 5 & Number of grains per ear & 1.01 \\
\hline 6 & Thousand Grain weight (g) & 2.02 \\
\hline 7 & Flag leaf area $\left(\mathrm{cm}^{2}\right)$ & 15.52 \\
\hline 8 & Chlorophyll content (SPAD Unit) & 6.00 \\
\hline 9 & Relative water content (\%) & 16.94 \\
\hline 10 & Relative water loss (\%) & 2.22 \\
\hline 11 & Canopy temperature $\left({ }^{0} \mathrm{C}\right)$ & 1.41 \\
\hline 12 & Canopy temperature depression $\left({ }^{0} \mathrm{C}\right)$ & 2.02 \\
\hline 13 & Grain yield $^{-1}(\mathrm{~g})$ & 4.48 \\
\hline
\end{tabular}

\section{Cluster mean values}

Mean values of seven clusters of 32 genotypes is presented in Table 3. On the basis of cluster mean, flag leaf area and canopy temperature depression showed maximum values in cluster
1. Cluster II recorded maximum mean value for thousand grain weight, number of grains per ear and minimum values for number of days to maturity. Cluster IV recorded high mean value for tillers per plant, relative water content and grain yield per plant whereas it 
recorded minimum mean value for relative water loss and canopy temperature. Cluster VI recorded minimum mean value for days to fifty per cent flowering. On the basis of divergence and cluster mean it may be concluded that maximum heterosis and good recombinant would be possible from crosses between genotypes of clusters I, II, IV and VI cluster.

\section{Percent contribution towards total divergence}

The characters contributing maximum to the $\mathrm{D}^{2}$ values are to be given greater emphasis for deciding the cluster for the purpose of further selection.(Singh et al., 2012) Under the present investigation the maximum contribution towards the total divergence as given in table 4 was exhibited by days to flowering $(40.32 \%)$, followed by relative water content $(16.44 \%)$, flag leaf area $(15.52 \%)$, days to maturity $(7.46 \%)$, chlorophyll content (6\%), grain yield per plant (4.48\%), tillers per plant $(3.63 \%)$, relative water loss (2.22\%), plant height $(2.02 \%)$. Therefore, these characters should be given importance during hybridization and selection in the segregating population for improvement of yield and its component traits.

Under present investigation 32 genotypes were grouped into six clusters. The genotype of the cluster II and VI exhibited maximum divergence. The higher inter cluster distance indicated the presence of wide diversity among the genotypes included among these clusters. Hybrid produced from the selected genotypes from these clusters showing high inter cluster distance may produce appropriate transgressive segregation of high magnitude of heterosis. Cluster mean values indicated that genotypes like Cross 3 RIL 15 from cluster IV, PBN-51 from cluster IV, Cross 3 RIL 30 from cluster VI could be used as potential donors for hybridization program to produce desirable recombinant genotypes with high grain yield suitable for heat stress conditions. The trait namely days to flowering, relative water content, flag leaf area, days to maturity, chlorophyll content and grain yield per plant contributed more than $70 \%$ towards divergence. Hence, these characters should be given importance during hybridization and selection in process for improvement of yield and its component traits.

\section{References}

Cossani, C.M., Reynolds, M.P. (2012) Physiological traits for improving heat tolerance in wheat, Plant Physiol, 16(2): 1710-1718.

Fu, Y., Somers, D. (2009). Genome wide reduction of Genetic Diversity in Wheat Breeding Crop Science., 49: 161-168.

Hailegiorgis, D., Mesfin, M. and Genet, T. (2011) Genetic Divergence Analysis on some Bread Wheat Genotypes Grown in Ethiopia. Journal of Central European Agriculture, 12(2): 344-352.

Hansen, J., M. Sato. (2012). Perception of climate change, Proc. Natl. Acad. Sci. U.S.A. 109 E2415-E2423. hybridization and in vitro culture technique. PhD Thesis. Rajshahi University,

Jain, K.C., Pandya, B.P. and K. Pande. 1981. Genetic divergence in chickpea. Indian Journal of Genetics. 41: 220- 225.

Kaur, V. and Behl, R. K. 2010. Grain yield in wheat as affected by short periods of high temperature. Cereal Res. Commun. 38: 514-520.

Keeling, P.L., Bacon, P., Holt D.C. (1993) Elevated temperature reduces starch deposition in wheat endosperm by reducing the activity of soluble starch synthase, Planta, 191: 342-348.

Kumar, A., R.B Ram., Singh, S. P. (2002). Studies on yield and its component 
traits in bread wheat (Triticum aestivum L.). New Botanist, 29(-14): 175-180 (Abst. 2002/08 -2003/10).

Larkindale, J., Knight, M.R. (2002). Protection against heat stress-induced oxidative damage in Arabidopsis, Plant Physiol, 128: 682-695.

Lobell, D. B., Sibley, A., Ortizmonasterio, J.I. (2012). Extreme heat effects on wheat senescence in India. Nat. Clim. Change, 2: 186-189.

Lokhande G. D., Pawar, B. B., Dumbre A.D. and Thete, R.Y. 1987. Genetic divergence in garlic (Allium sativum L.). Current Research Report 3: 98-99.

Mahalanobis P.C. 1936. On generalized distance in statistics. Prod. Nat. Acad. Sci. (India), 2: 49-55.

Mohanty, B. K., Prusti, A. M. (2002) Mahalanobis's generalized distance analysis in onion. Research on Crops, $3,142-144$.

Mondal, M.A.A., (2003) Improvement of potato (Solanum tuberosum L.) through hybridization and in vitro culture technique. PhD Thesis. Rajshahi University, Rajshahi, Bangladesh.

Ristic, H., Bukovnik, U., Prasad. P.V. (2007) Correlation between heat stability of thylakoid membranes and loss of chlorophyll in winter wheat under heat stress, Crop Sci, 47: 2067-2073.

Rao, C. R. 1952. Advanced statistical methods in biometric research. A Division Of Macmillan Publishing Co, Inc New York; Collier-Macmillan Publishers; London.
Ristic, Z., Bukovnik, U., Prasad, P.V.V. (2008). Heat-induced accumulation of chloroplast protein synthesis elongation factor in wheat, Aust. J. Plant Physiol., 165: 192-202.

Samsuddin, A.K.M. 1985 Genetic diversity in relation to heterosis and combining analysis in spring wheat. Theor. Appl. Genet. 70: 306-308.

Sial, AM., Arain, MA., Khanzada, S., Dahot, MU. and Nizamani, NA. 2005. Yield and quality parameters of wheat genotypes affected by sowing dates and high temperature stress. Pak J. Bot. 37: 575-584.

Singh, R. K., Dubey, B. K., Gupta, R. P. (2012) Studies on variability and genetic divergence in garlic (Allium sativum L). Journal of Spices and Aromatic Crops, 21 (2): 136-144.

Singh, R.B., Gupta, M.P. (2011). Multivariate analysis of divergence in upland cotton. Indian Journal of Genetics. 28, 151-157.

USDA (2020/21) Crop Production Summary. United State Department of Agriculture. [Online] Available at http://fas.usda.gov/psdonline/circulars/ production.pdf. p 21.

Verma, PN., Singh BN., Singh G. 2014.Genetic diversity analysis for yield and other agronomic traits in bread wheat under water logged sodic soil condition. Journal of Wheat Research. 6(1): 51-58.

Wahid, A., Gelani, S., Ashraf, M., Foolad, M. R. 2007. Heat tolerance in plants, an overview. Environment and Experimental Botany, 61: 199-223.

\section{How to cite this article:}

Harpreet Singh, Bikram Singh, Surbhi Kohli, Ashish Sheera, Om Prarkash and Faisal Butt. 2021. Study of Genetic Diversity of Recombinant Inbred Lines in Bread Wheat (Triticum aestivum L.) for Heat Tolerance. Int.J.Curr.Microbiol.App.Sci. 10(02): 1239-1245. doi: https://doi.org/10.20546/ijcmas.2021.1002.145 